Original Research Paper

\title{
Pre-Service Teachers and Educators Perception toward Use of Technology in Education-Challenge and Reforms for West Azerbaijan Iran
}

\author{
Mahsa Moshfeghyan \\ Director of Quality Assurance, Department of English, Cihan University of Erbil-Iraq
}

Article history

Received: $12-12-2016$

Revised: $15-02-2017$

Accepted: 28-02-2017

Email: m.mahsa@live.com

\begin{abstract}
Lack of proper use of Information and Communication Technologies (ICT) in modern education and training for pre-service teachers-PSTs- (students who are not yet teaching professionally) is confronting globalized education system. Iran is not exception where the use of ICT is rather for entertainment and amusement purposes. PST perceptions and attitudes do affect quality of education and hence, performance of students. Structured questions were made to delineate the perceptions of PST regarding use of ICT education of West Azerbaijan (Iran). The study found that most of universities PSTs are adapting ICT in their lectures but not in its optimal capacity. Still many challenges and opportunities are there to improve the usage of ICT in education and training for PSTs and this calls for up-to-date reforms. New academic equipments equipped with flux ICT and uses of audio-visual aids for lecturing are highly recommended. Further study suggested the school based training module for PSTs to policy makers and educationalist who involved in training programs.
\end{abstract}

Keywords: Educational Technology, Education and Training, ICT, PreService Teachers, West Azerbaijan Iran

\section{Introduction}

Competency in ICT is recognized as one of the main competencies for teachers and it is essential for integration of technology in their future teaching for PSTs (Aslan and Chang, 2016; Selvi, 2010). So, ICT must be embedded into education system particularly for PSTs (Northcote and Lim, 2009). In reality, teachers facilitate student creativity, innovation and learning by using their knowledge of the technology, subject matter, teaching and learning (ISTE, 2008). In this regard, ICT plays an important role in enabling teachers and students to learn and teach more efficiently and effectively. The integration of ICT into education necessitates teachers to be competent in the use of ICT. In other words, teachers are required to have enough ICT knowledge and competencies to make use of ICT for education (Goktas et al., 2009). Moreover, Xiong and Lim (2015; Aslan and Chang, 2016) indicated the importance of learning outcomes, teacher education programs on different aspects of
PSTs learning and the significant role of ICT-related courses on PSTs' teaching practices. However, Tondeur et al. (2012) noted that even if many institutions offering educational technology courses for PSTs to help them develop technology skills, PSTs still do not feel prepared for using technology in the classroom. He suggested that PST education should not only focus on how to use technology, but also how technology can be used for learning and teaching. Hence, Xiong and Lim (2015) suggested that ICT learning experiences, feedback and reflections from Pre-Service Teachers (PSTs) are essential to refine and revise teacher education program. Similarly, Bansilal (2015) explored that mathematics PSTs used technology more often in their own learning than in their teaching. He also recommended that these mathematics PSTs should be provided with latest technology such as mathematic software for their improvement in learning. In this regard, it is critical to investigate PSTs' experiences and perception with contemporary technologies in their technology related 
and others courses not only to investigate their level of technology integration as future teachers, but also to identify certain needs and opportunities in teacher education programs for supporting PSTs and improving their future technology applications.

Born after $1980 \mathrm{~s}$ and surrounded by era of ICT and digital technologies, new generation of PSTs are named as "digital natives". But few empirical studies are available on their experiences and competencies with digital technologies (Prensky, 2001; Chen et al., 2010). Chen et al. (2010) reported that even if digital technologies impact multiple aspects of PSTs' lives critically, there is an important gap between their everyday experience with technology and their technology use for educational purposes. Over the last two decades, studies have showed that PSTs' education competencies in ICT have great impacts on tomorrow's learning and teaching. This has been a key research focus in PST education. There have been continuous efforts to develop and design the existing ICT usage in education curriculum in the area of ICT integration throughout the globe (Jimoyiannis, 2010; Chai et al., 2012). Iran is not an exception for the use of ICT in education system for development of the country; however, as Teimoornia et al. (2011) state that the use of ICT in Iran is more for amusement rather than education purposes.

Education in Iran is highly centralized and is divided into primary education and higher education and the ministry of education under supervision of Ministry of Science and Education is in charge of educational planning, financing, administration, curriculum and textbook development. The fourth five-year development plan (2010-2015) envisages upgrading the quality of the educational system at all levels, as well as reforming education curricula and developing appropriate programs of vocational training, a continuation of the trend towards labor market oriented education and training with the aid of technology and ICT usage. There are both free public schools and private schools in Iran at all levels, from elementary school through university. Teacher training, grading and examinations are also the responsibility of the ministry. At the university level, however, every student attending public schools is required to commit to serve the government for a number of years typically equivalent to those spent at the university, or pay it off for a very low price (typically a few hundred dollars).

Developing countries, including Iran, have faced challenges related to the pressure for national competitiveness in globalized knowledge-based economy against an existing reservoir of under trained and untrained teachers; and the challenges of cross border education advances in ICT and the resultant need for leveraging modern information and communication technologies in the training of the teachers. As in many other developing countries, Iran universities and/or colleges do not meet adequately either current or projected demand for teacher education and training. This is perhaps the major challenge in developing countries. For instance, Bansilal (2015) explored that developing countries may be sometimes beset with challenges such as limited access to efficient technological software, teachers with inadequate training and support and poorly managed education and school systems. Delfino and Persico (2007) found that for developing countries globalization and ICT revolution are still the biggest task. Furthermore, Bladergroen et al. (2012) found that in developing countries integrating ICT in teaching and learning in schools is the educators' lack of the necessary technical skills is one of the major challenges.

Based on previous discussion, our study will contribute in the literature by several ways. Firstly, focusing on how much PSTs perceive the importance of use of ICT and new technology in education system. No doubt bunch of literature can be found regarding the importance of ICT in education; however, use of ICT and technology for PST training in the light of educators and student prospective still need further research. Hence, this study is designed to investigate the use of technology by young student teachers, can contribute to the knowledge base that emerging resource economies such as Iran need in order to make important policy decisions. Secondly, identifying the major hurdles faced by PSTs in education and the use of ICT in teaching. ICT and its use in education is changing due to flux nature of ICT hence, research is still under process in developing countries generally and in Iran particularly. This study will contribute in the literature by investigating the hurdles in the use of ICT in education. This is the first half of the story. Thirdly, the second half of story i.e., solution based research, involves the opportunities and reforms needed to remove these hurdles. Most of previous research regarding solution to hurdle faced by PST is western based. Every country has different nature and behavior of people. We cannot generalize these solutions to all countries, especially Iran, which has Islamic background. Hence, this study will give firsthand information on the opportunity and reforms needed against the hurdle faced by PSTs in developing countries. Lastly, most of previous researches in developing countries are reactive to some specific issues encountered. However, this study is designed for proactive approach so that policy recommendations can be given to all other developing countries that are facing similar challenges for ICT usage in education. It is hoped that the study will add to knowledge about the enabling and constraining factors associated with the use of technology in the teaching 
and learning. However, these results may vary to some extend as a matter of fact of non-homogenous nature of developing countries.

The study is systematically organized as follows: In the first part detailed introduction about importance of ICT for PST in education is presented. Education system of Iran and statement of problem is also given in this part. In second part detailed theoretical and empirical literature is given. The third part shed a light on methodology used for this study. In the fourth part results and discussion are given. In the fifth and last one, conclusion and policy recommendations are presented.

\section{Literature Review}

Based on research concerning the influence and persistence of beliefs about teaching that pre-service teachers (students who are not yet teaching professionally) bring with them to their courses, this study predicates the belief that teachers' perceptions impact teachers' behaviors. Through "Pygmalion Effect" teachers' expectations impact performance of students as noted by Rosenthal and Jacobson's (1968). Teachers' attitudes and perceptions directly impact outcomes for students in education (Woodcock, 2010). Teachers' perceptions are often formed during their teacher education programs (Woolfolk-Hoy and Spero, 2005). Hence, it is essential to examine teaching and learning within PST education. Of particular interest are the structures, methods and experiences within teacher education programs to prepare teachers to educate students. In order to do so the contextual classroom research (Cross, 1998) becomes necessary. This intersection of teaching and discovery (research), within the Scholarship of Teaching and Learning (SoTL) guided the theoretical approach (Boyer, 1990) of proposed study. In doing so systematically investigate questions related to student learning-the conditions under which it occurs, what it looks like, how to deepen it and so forth-become important and do so with an eye not only to improving the classroom but to advancing practice beyond it (Hutchings and Shulman, 1999). The goal of this research study was to improve student learning and teacher education and hence, hurdles of use ICT in education and remedies to these hurdles.

As noted by Lim and Khine (2006) that the capability of technology to transform learning and teaching, the use of technology and ICT in the classes remained minimal and peripheral and even teachers do not use technology effectively despite the fact that research evidence clearly stated its role and importance. For instance, Jaffer et al. (2007) showed that ICT uptake for learning and teaching was below from expected level than that of potential usage of ICT in South Africa. This further created anxiety among the students regarding preparedness and compounded linguistic challenges in a multilingual context. This might be due the reason teachers $(81.8 \%)$ did not use computers for learning and teaching and remaining used computer infrequently and often used drills and games in the classes.

This lack of usage ICT in educational institutes is the big dilemma of developing countries. However, this problem can be encountered by training PSTs about ICT usage in the classes (Fajet et al., 2005; Teo, 2009; Bladergroen et al., 2013). For instance, Bladergroen et al. (2013) found that the success in ICT usage lay in training in-service (educators) and pre-service personnel. The benefits will then cascade to the end user and those institutes who wanting to introduce ICT training for inservice teachers and PSTs. They argued that the context in which ICT training happens is the first process which can support or inhibit the integration of ICT in information-rich pedagogical practices and teacher development. Further, they noted that the involvement and support of the institutional management in both settings have a substantial impact on the motivation of the sample groups approach to the ICT training and hence the role of facilitator was still crucial despite affordances and opportunities of ICT in education. This is the reason proposed study took the perception of PSTs and educators for the use of ICT in Iran where Teimoornia et al. (2011) noted that use of ICT in Iran is for amusement rather than education purpose. If the proper intention will not be given, country may face problems in the Curriculum, for example, students may be limited to some knowledge which cannot meet their needs and they may not be able to use lesson plans, so they would face problems. Also, they would waste their energy and time (Imam, 2003; Teimoornia et al., 2011). This is even dogma of other emerging countries such as South African where Makura (2014; Cross and Adam, 2007) reported that most lecturers/institutes do not use ICTs for teaching, Thai Land where James (2008) indicated that fewer academics utilize ICTs and Turkey where Somekh (2008; Aslan and Chang, 2015) reported that teachers use ICTs in their teaching at a low level.

The teacher is the key to effective use of technology in the educational system and it is important for teachers to understand the precise role of technology in teaching and learning so that they can learn to cope effectively with the pressure created by the continual innovation in educational technology and constant need to prioritize the use of technology (Zhao et al., 2001). Research has shown that teachers' perceptions and attitudes towards technologies influenced the effective use of these technologies in learning and teaching (Paraskeva et al., 2008). While stakeholders in education expect teachers to engage technology in ways which are consistent with their beliefs that technology will impact on teaching and learning, it must be borne in mind that teachers are faced with many variables that interact with each other to 
either facilitate or discourage the acceptance of technology. Some of these include personal factors, such as computer self-efficacy (Paraskeva et al., 2008), technical factors such as technological complexity (Thong et al., 2002) and environmental factors such as facilitating conditions (Ngai et al., 2007).

\section{Methodology}

Structured questionnaire was developed for data collection for which simple random sampling techniques were used. We selected colleges and universities for our data collection offering diplomas, bachelor, masters and $\mathrm{PhD}$ degrees in various fields. The sample size has been targeted to 146 teacher's education and 110 faculty members, staff and manager's teacher education college in west Azerbaijan Iran. Therefore all colleges of west Azerbaijan had been used for sampling. Distribution of sample size among PSTs were 61 (42\%) bachelor students followed by $59(40 \%)$ diploma and others such as master, $\mathrm{PhD}$ etc. $26(18 \%)$, respectively. As for lecturers, staff and managers of colleges and universities are concerned; we selected randomly 76 lecturers, 25 staff members and 9 managers, respectively.

The researchers personally distributed and collected questionnaire from 146 teacher education 110 faculty members, stuff and manager teacher educational college in 2012-13. Data was collected in two parts: Part one involved 4-point agreement scale (strongly agree, agree, disagree and strongly disagree) developed for PST. In part two, 5-point agreement scale (strongly agree, agree, undecided, disagree and strongly disagree) was developed for university lecturers and staff.

\section{Results and Discussion}

This study consists of two parts. In the first part, the use of PST perception and experience is given for content and course development and hence importance and use of technology for teaching and learning. In this part problems and challenges faced by PSTs are also given. In the second part of study, perception of staff, lecturers and manager of faculty are given. In this part, perception about technology usage in learning and teaching is given with addition to reforms needed for West Azerbaijan Iran education system for PST.

Part One: Perception of Pre Service Teachers (PSTs) for Education System and use of ICT

\section{Facilities of Educational Technology (ET) and Currents Needs}

From the result of Fig. 1, it can be seen that $60 \%$ of students have agreed that the facilities of educational technology in West Azerbaijan universities are relevant with currents needs of the teacher education. At the same time $64 \%$ of students have agreed that lecturers do not use them correctly. $59 \%$ of students have agreed that the facilities are not relevant. $57 \%$ teachers' educators have expressed that facilities are not sufficient in West Azerbaijan universities. The proposed study results are true depiction of developing countries where, for example, Gulati (2008) reported that poor access to internet, lack of policy, lack of financial resources and poorly and limited trained teachers are the main hurdles in ICT usage in educational institutes. Further, Cantrell and Visser (2011) were on the opinion that in developing countries educational institutions have not successfully managed to institutionalize digital technology. This necessitates for the policy makers and educational anthropologist to focus on ICT usage in education so that these developing countries can become part of globalization.

\section{Facilities of ET for Teachers Education}

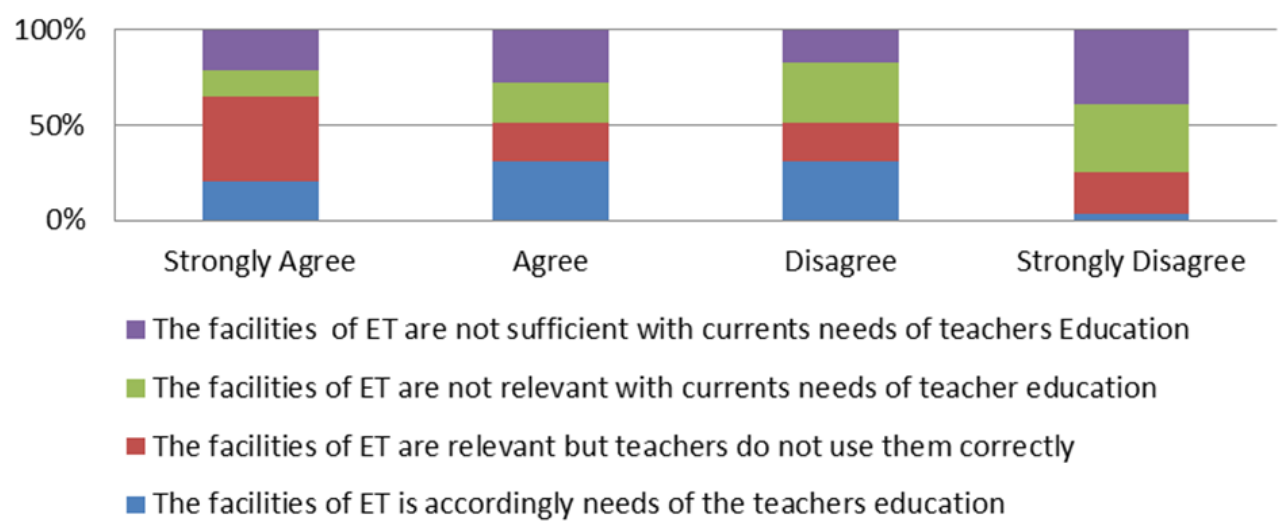

Fig. 1. ET facilities provided for teachers education 


\section{Use of ET of Teaching Methodologies (TMs) for Lecturing}

Regarding the current teaching methodologies, students have agreed strongly that the lecturing method is one of the dominant teaching methodologies applied by professors in West Azerbaijan's universities. They have agreed that teaching methodologies based on debate and participation and inter-professors seminars are very common in West Azerbaijan's universities. But students have disagreed that active teaching methodologies based on audio-visual aids are very common among professors in West Azerbaijan's universities. They have strongly disagreed that teaching methodologies which make use of computer and technology based on satellite and cable teaching networks are very common among professors in West Azerbaijan's universities.

Out of 146 students surveyed about the current teaching methodologies in universities of West Azerbaijan province, $47 \%$ strongly agree with the view that the lecturing method is one of the dominant teaching methodologies applied by professors in their university while $22 \%$ agree with it. On the other hand, $24 \%$ disagree with this view and $7 \%$ strongly disagree with it. $15 \%$ strongly agree with the view that the teaching methodologies are based on debate along with inter professors seminar while $45 \%$ agree with it. While $26 \%$ disagree with this view and $14 \%$ strongly disagree with it. $12 \%$ strongly agree with the view that teaching methodologies based on audio-visual aids are very common among professors in their university while $28 \%$ agree with it and 50\% disagree with this view and 10\% strongly disagree with it as can be seen in Fig. 2. 19\% strongly agree with the view that teaching methodologies that make use of computers are very common among professors in their university while $24 \%$ agree with it. Our results, however, are somehow different from Stols et al. (2015) who found that the majority (86\%) of teachers used computers in their lecturing and preparation for classes. In our study $45 \%$ disagree with this view and $12 \%$ strongly disagree with it. Only $4 \%$ strongly agree with the view that teaching methodologies which make use of technology based on satellite and cable teaching networks are very common among professors in their university while $10 \%$ agree with it. On the other hand $5 \%$ disagree with this view and $81 \%$ strongly disagree with it.

We can conclude that emerging economies like Iran should make use of ICT through use audio visual aid in their education and learning institutes. For instance, Jaffer et al. (2007) suggested that ICT use was a useful strategy in addressing persistent learning and teaching challenges in South Africa. From the statistics given above a proactive approach becomes necessary for developing economies like Iran where
$50 \%$ disagree and $10 \%$ strongly disagree that teachers used ICTs. Even our results are compatible with Stols et al. (2015) who found that the majority of mathematics teachers' perception is inclined toward the use of educational technology in education. They explored that majority of respondents (86.4\%) strongly approved with the introduction of new technology in education and its role in teaching and learning. These respondents considered technology in lecturing as great asset for classroom. This debate shows that how ICT usage is fruitful for PSTs and learning and teaching institutes of economies like Iran.

Part 2: Perception of Staff, Lecturers and Managers of Faculty Regarding use of ICT and Education of West Azerbaijan Iran

\section{Use of ET for Teaching}

University teacher educators have indicated that special use of academic equipment in simulated classes and emphasis on the use of teaching technology is necessary. They have also extremely agreed that preparing modern academic equipment based on changes and appropriate for teaching is also needed. Respondents have disagreed with adding to academic credits and introducing teaching technology.

Out of 110 university teacher educators, reinforcement of teacher training programs for using teaching technology. The results showed that $36 \%$ strongly agreed with the viewpoint that it is advised to make special use of academic equipment in simulated classes and emphasis on the use of teaching technology in teaching confirming the results of Teo (2009), 14\% agreed with it while $6 \%$ of respondents were undecided about it as cab be seen in Fig. 3. On the other hand, $17 \%$ disagreed with the view while $27 \%$ totally disagreed with this viewpoint. $68 \%$ strongly agreed with the viewpoint that it is necessary to prepare modern academic equipment based on changes and appropriate for teaching, 20\% agreed with it while $0 \%$ of respondents were undecided about it. On the other hand, $2 \%$ disagreed with the view while $10 \%$ totally disagreed with this viewpoint. $37 \%$ strongly agreed with the viewpoint that it is necessary to add to academic credits and introduce teaching technology as suggested by Teo (2009), 8\% agreed with it while $2 \%$ of respondents were undecided about it. On the other hand, $19 \%$ disagreed with the view while $34 \%$ totally disagreed with this viewpoint. Latter two figures $(19 \%$ disagreed and $34 \%$ totally disagreed) are worrying situation as they assigned great importance to their personal characteristics and less importance to pedagogical training. Teacher educators need to be aware of the research on student perceptions, which shows that core beliefs tend not to change over time (Griffin, 1989). 


\section{TMs Adopted by Teachers}

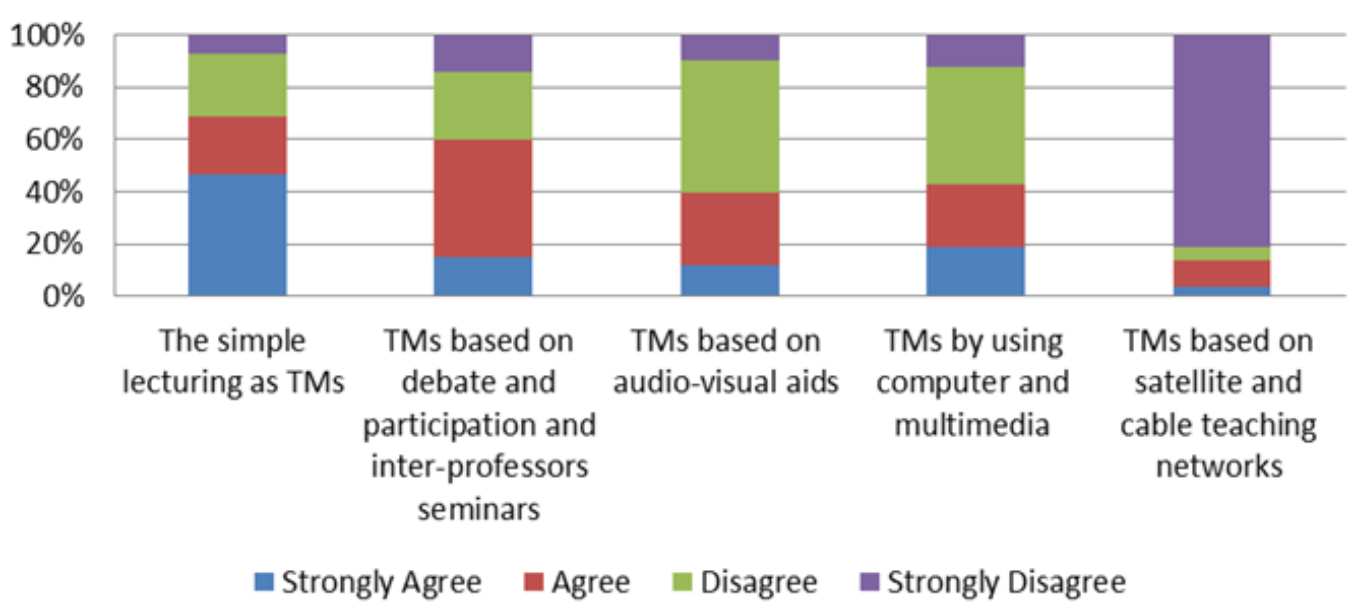

Fig. 2. TMs adapted by teachers

\section{Use of ET for Teaching PST}

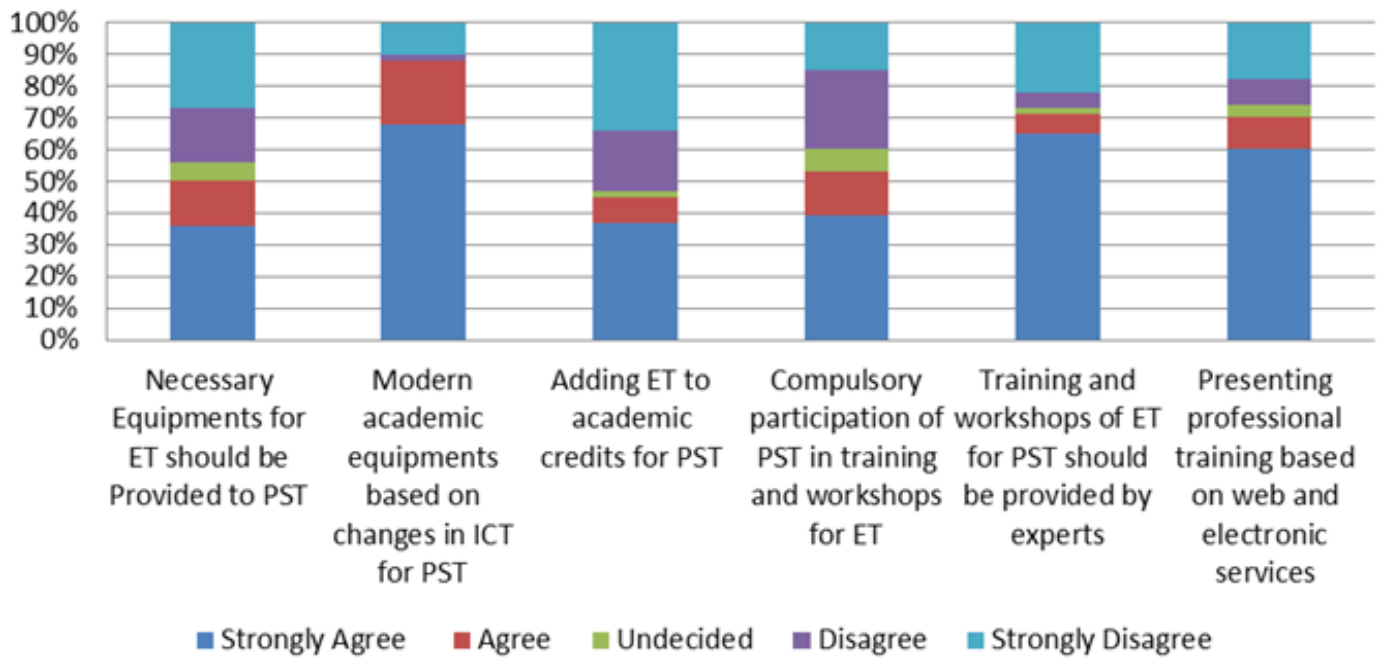

Fig. 3. Use of ET for teaching PSTs

Furthermore, study's results are compatible to Aslan and Chang (2016) who indicated that ICT courses, perceived ICT competence and pedagogical knowledge significantly predicted $(17 \%)$ integration of ICT into teaching practice in Turkey through statistical analysis.

Out of 110 universities teacher educators, surveyed for measures to be taken methods which are presented to improve and upgrade teaching methodologies. About 39\% have strongly agreed with increasing the level of trainings by presenting them informally and forcing personnel to participate in these programs such as workshops and $40 \%$ agreed with this view, $7 \%$ are undecided about it. On the other hand, 25\% disagree with this view and $15 \%$ strongly disagree with it. Regarding the university professor and personnel answer about occupational and professional training by inviting experienced professors with an emphasis on receiving professional and economic benefits, $65 \%$ strongly agree, $6 \%$ agree with this view. $2 \%$ are undecided about it, on the other hand $5 \%$ disagree with the view and $22 \%$ strongly disagree with it. These results confirmed the hypothesis of Bladergroen et al. (2013) that facilitate educators to build the connection between digital technologies and their pedagogical practices and Gulati (2008) who suggested economic benefits and financial resources 
distribution to ICT development. This further be supported by Makura (2014) who reported that such initiatives makes a strong case for massive investment in e-learning programmes especially among academic staff. This can be done through hire expert and experienced in this field. About presenting professional training as web and electronic services by encouraging personnel to make use of the benefits of this modern method, $60 \%$ have strongly agreed with this view, $10 \%$ agree with it, $4 \%$ are undecided about it; on the other hand, $8 \%$ disagree with this view and $18 \%$ strongly agree with it. However, Stols et al. (2015) found that 37.5 and $36.4 \%$ teachers had access to internet in the classes and homes, respectively who might be hesitant to utilise technology in their teaching.

Based on above discussion study concluded that universities of teacher educators have indicated that increasing the level of trainings by presenting them informally and forcing personnel to participate in these programs such as workshops is an important method for presenting while servicing-training to improve and upgrade the participants. They are also extremely agreed that occupational and professional training by inviting experienced professors with an emphasis on receiving professional and economic benefits is a helping method while servicing training. Respondents have extremely believed that presenting professional training as web and electronic services by encouraging personnel to make use of the benefits of this modern method also important to improve and upgrade of their persona and developing economies as a whole.

\section{Problems of PST in West Azerbaijan Iran for ICT Usage}

Form the result of Fig. 4 we can conclude that university teacher educators extremely agreed that increasing the number of applicants in teacher training universities and centers and the lack of educational space and facilities is one of the upcoming challenges for personnel. Respondents also strongly agreed that the rapid progression of communication and Information Technologies (ICT) and the lack of educational specialist and efficient personnel are the other upcoming difficulties for personnel. Respondents extremely believed that the rapid increase of educational expenditure and the lack of the required fiscal resources also will become a challenge, in their opinion.

Our results are similar to Marais (2016) who explored that lack of facilities for PSTs in using new technology in overcrowded classes is a big problem for teachers. They cannot apply varieties of teaching strategies.

\section{Problems of PST in West Azerbaijan Iran for ICT Usage}

From Fig. 5 we can conclude that university teacher educators extremely agreed that increasing the capacity for admitting students appropriate for the needs of society based on the development programs of higher education by taking permissions of expanding educational spaces can be one of the good solutions for improving and solving pointed obstacles in teacher training universities. Respondents also strongly agreed that increasing the number of whileservice periods and remedial courses for official and educational personnel by holding seminars is another solution. Respondents have also extremely believed that holding seminars for analyzing the future challenges and problems and the appropriate solutions and strategies can be a solution for improving and solving the difficulties in teacher training in universities.

\section{Problems Faced by PST}

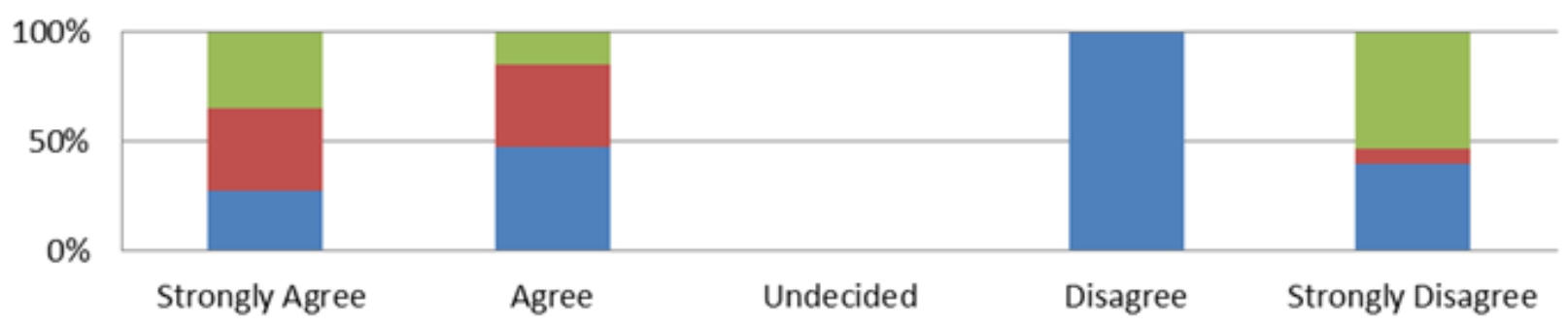

- Lack of resources while ever increasing educational expenditures

- Lack of educated and efficient personal and rapid progression of ICT for PST

- Lack of training centre, space and facilities PST

Fig. 4. Problems of PSTS in West Azerbaijan Iran for ICT usage 


\section{Remendies for Problems in Hand for PST training}

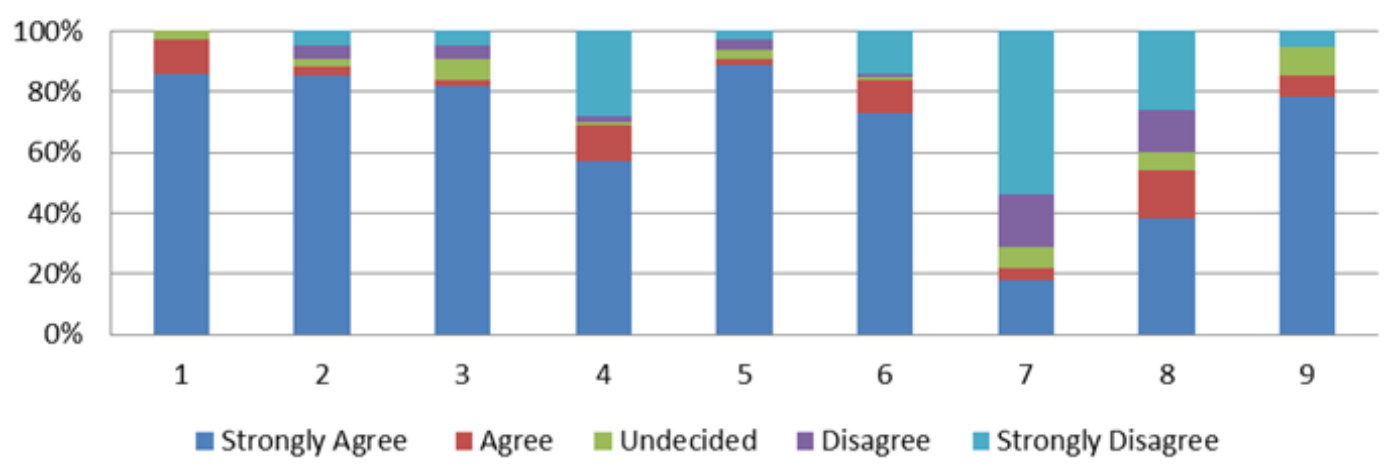

Fig. 5. Solutions to obstacles for PSTs in learning and teaching

For example, Fig. 5 columns 4-6 implies that university teacher educators have indicated that applying final and formal employment of professors, lecturers and personnel in teacher training universities instead of provisional or hire employments is fruitful for upgrading human resourcing in teacher training universities. Respondents also strongly agreed that changing the employment approach in universities by considering scientific aspects and experiences of official and educational personnel is beneficial. Respondents have extremely believed that improving the condition for job promotion by presenting annual evaluation methods for official and educational personnel is fruitful for upgrading human resourcing. Similarly, rows 7-9 show that university teacher educators highly disagreed that establishing and modulating communication offices to interact with schools in teacher training universities will decrease the boundaries among teacher training universities, schools and centers. This is very important for on the job training. This can be done by School Based Training Modules (SBTM). For example, Richter (2016) recommended that SBTM is good alternative teacher training programme for the countries that experience teacher shortage. Awareness can be created by community and civil participation for emerging challenges confronting to education. On the other hand, respondents are more agreed that changing the research approaches with emphasis on the participation in social and civil activities by making use of civil organizations will help to decrease those boundaries. They have strongly believed that establishing scientific cooperation and collaboration with other universities and higher education centers is beneficial for teacher training courses.

Where 1 . Increasing the capacity for admitting students, 2. Increasing the number of training courses by holding seminars, 3. Holding seminars for analyzing the future challenges and their appropriate solutions, 4. Permanents expert trainers for PST in teacher training universities, 5 . Changing the employment approach for experienced educational personnel, 6. Improving the condition for job promotion, 7. Establishing communication among schools, teacher training centers and teacher training universities, 8. Emphasis of the participants in social and civil activities and 9. Establishing collaboration with other universities and higher education.

The majority of respondents $(90 \%)$ thought that changing employment approach of experienced educational personnel is a good tool for effective education in Iran, whereas $79 \%$ of respondents believed that establishing communication among schools, teacher training universities and teacher training centers can be good tool for educational reforms. This can be done for on the job training and holding seminars as can be seen in Fig. 5. On the job training is effective once PSTs work in schools as internship programs. Hence, the proposed study recommends SBTM as suggested by Richter (2016). No doubt he recommended this method for shortage of teachers but it can also be an effective method for PSTs training who would train the future generation.

\section{Conclusion and Policy Recommendations}

Competency in ICT and digital literacy has become first step for the digital learners, especially for the PSTs. In this respect, using technology managing ICT in an efficient manner for rapid change in education and training has become necessary. The participation of social, civil society, civil organizations, universities and higher education for future problem and remedial course for flux ICT usage for changing modern education and training need is very necessary. In this respect, PST who will be next trainer for future education system will be fully equipped with ICT and its use in education and development of the country. It is found in the study that 
West Azerbaijan (Iran) are fully equipped with current needs of the teacher education; however, improvements are still required due to flux nature of ICT. It is found that traditional lecturing methods based on debate and participation were used by teachers but use of audiovisual aids were less prevalent. Scientific and extracurricular competitions were there but PSTs hardly found appropriate jobs according to their skills and needs. Among other things, fewer training institutes against increasing applicants, lack of educational space and facilities, rapid progression of ICT, lack of educational specialists and efficient personnel for training PSTs and increase in educational expenditures are major challenges that face education in West Azerbaijan Iran. Similar to other developing countries, effective training for PSTs is not being provided in Iran. This necessitates on the job training such as school based training module for PSTs for effective training utilization as a proactive approach.

It is recommended that active teaching methodologies based on audio-visual aids based on satellite and cable teaching should be there for PST for optimal use of ICT for society. It is also recommended that formal and final full time professors, lecturers and personal in teacher training should be there rather than part hired personnel. Further, the study recommended the school based training module for on the job training of PSTs which can be ice breaking in developing countries where education facilities are not up to the mark such as over crowdedness, less space for newly admitting students, shortage of permanent trainers and poorly training provision.

The main conclusions of the experimental work should be presented. The contribution of the work to the scientific community and its economic implications should be emphasized.

\section{Acknowledgement}

I am thankful to Cihan University for supporting research.

\section{Funding Information}

Author acknowledges the Cihan University for supporting research funds for this manuscript.

\section{Author's Contributions}

Mahsa Moshfeghyan: She is the only author and designer of the manuscript in hand.

\section{Ethics}

This paper has never published before and/or presented in any conference.

\section{References}

Aslan, A. and Z.H.U. Chang, 2015. Pre-service teachers' perceptions of ICT integration in teacher education in Turkey. Turkish Online J. Educ. Technol., 14: 97-110.

Aslan, A. and Z.H.U Chang, 2016. Investigating variables predicting Turkish pre-service teachers' integration of ICT into teaching practices. Brit. J. Educ. Technol., 48: 552-570. DOI: $10.1111 /$ bjet.12437

Bansilal, S., 2015. Exploring student teachers' perceptions of the influence of technology in learning and teaching mathematics. South Afr. J. Educ., 35: 1-8. DOI: 10.15700/saje.v35n4a1217

Bladergroen, M., W. Chigona, A. Bytheway, S. Cox and C. Dumas et al., 2012. Educator discourses on ICT in education: A critical analysis. Int. J. Educ. Dev. Us. Inform. Commun. Technol., 8: 107-119.

Bladergroen, M., W. Chigona, A. Bytheway, C. Dumas and S. Cox et al., 2013. The dynamics of offering ICT training to pre-service and in-service teachers in a South African context. Proceedings of the International Conference on e-Learning, (ICEL' 13).

Boyer, E., 1990. Scholarship Reconsidered: Priorities of the Professoriate. 1st Edn., Carnegie Foundation for the Advancement of Teaching, Princeton, NJ.

Cantrell, S. and L. Visser, 2011. Factors influencing the integration of technology to facilitate transfer of learning processes in South African, Western Cape Province schools. Q. Rev. Distance Educ., 12: 275-285.

Chai, C.S., J.H.L. Koh, J.H.N. Ho and C.C. Tsai, 2012. Examining preservice teachers' perceived knowledge of TPACK and cyberwellness through structural equation modeling. Austral. J. Educ. Technol., 28: 1000-1019.

Chen, W., C. Lim and A. Tan, 2010. Pre-ervice teachers' ICT experiences and competencies: New generation of teachers in digital age. Proceedings of the 18th International Conference on Computers in Education, Asia-Pacific Society for Computers in Education, (SCE’ 10), Putrajaya, Malaysia.

Cross, K.P., 1998. Classroom Research: Implementing the Scholarship of Teaching. In: Classroom Assessment and Research: An Update on uses, Approaches and Research Findings, Angelo, T.A. (Ed.), New Directions for Teaching and Learning, Jossey-Bass, San Francisco, CA.

Cross, M. and F. Adam, 2007. ICT policies and strategies in Higher Education in South Africa: National and institutional pathways. Higher Educ. Policy, 20: 73-95. DOI: 10.1057 /palgrave.hep.8300144

Delfino, M. and D. Persico, 2007. Online or face-toface? Experimenting with different techniques in teacher training. J. Comput. Assisted Learn., 23: 351-365. DOI: 10.1111/j.1365-2729.2007.00220.x 
Fajet, W., M. Bello, S.A. Leftwich, J.L. Mesler and A.N. Shaver, 2005. Pre-service teachers' perceptions in beginning education classes. Teach. Teacher Educ., 21: 717-727. DOI: $10.1016 /$ j.tate.2005.05.002

Goktas, Y., Z. Yildirim and S. Yildirim, 2009. Investigation of K-12 teachers' ICT competencies and the contributing factors in acquiring these competencies. New Educ. Rev., 17: 276-294.

Griffin, G.A., 1989. A descriptive study of student teaching. Elementary School J., 89: 343-364. DOI: $10.1086 / 461579$

Gulati, S., 2008. Technology-enhanced learning in developing nations: A review. Int. Rev. Res. Open Distr. Learn., 9: 1-16.

Hutchings, P. and L.S. Shulman, 1999. The scholarship of teaching: New elaborations, new developments. Change, 31: 10-15.

DOI: $10.1080 / 00091389909604218$

Imam, G.T., 2003. The concept of information and literate in the age of technology and the curriculum. Roshd Magazine, Tehran.

ISTE, 2008. International society for technology in education 2008. ISTE standards teachers.

Jimoyiannis, A., 2010. Designing and implementing an integrated technological pedagogical science knowledge framework for science teachers professional development. Compu. Educ., 55: 1259-1269. DOI: 10.1016/j.compedu.2010.05.022

Jaffer, S., D. Ng'ambi and L. Czerniewicz, 2007. The role of ICTs in higher education in South Africa: One strategy for addressing teaching and learning challenges. Int. J. Educ. Dev. Us. Inform. Commun., 3: 131-142.

James, P.T.J., 2008. Academic staff perceptions of ICT and eLearning: A Thai HE case study. Turk. Online J. Educ. Technol., 7: 36-45.

Lim, C.P and M.S. Khine, 2006. Managing teachers' barriers to ICT integration in Singapore schools. J. Technol. Teacher Educ., 14: 97-125.

Makura, A.H., 2014. Students' perceptions of the use of ICT in a higher education teaching and learning context: The case of a South African University. Mediterranean J. Soc. Sci., 5: 43-47. DOI: $10.5901 / \mathrm{mjss} .2014 . \mathrm{v} 5 \mathrm{n} 11 \mathrm{p} 43$

Marais, P., 2016. "We can't believe what we see": Overcrowded classrooms through the eyes of student teachers. South Afr. J. Educ., 36: 1-10. DOI: $10.15700 /$ saje.v36n2a1201

Ngai, E.W.T., J.K.L. Poon and Y.H.C. Chan, 2007. Empirical examination of the adoption of WebCT using TAM. Comput. Educ., 48: 250-267.

DOI: 10.1016/j.compedu.2004.11.007
Northcote, M. and C.P. Lim, 2009. The state of PreService Teacher Education in the Asia-Pacific Region. In: Innovative Practices in Pre-Service Teacher Education: An Asia-Pacific Perspective, Lim, C.P., K. Cock, G. Lock and C. Brook (Eds.), Sense Publishers, Rotterdam, Netherlands, pp: 23-28.

Paraskeva, F., H. Bouta and A. Papagianna, 2008. Individual characteristics and computer self-efficacy in secondary education teachers to integrate technology in educational practice. Comput. Educ., 50: 1084-1091.

DOI: $10.1016 /$ j.compedu.2006.10.006

Prensky, M., 2001. Digital natives, digital immigrants. Horizon, 9: 1-6. DOI: $10.1108 / 10748120110424816$

Richter, B., 2016. Teacher training by means of a school-based model. South Afr. J. Educ., 36: 1-8. DOI: $10.15700 /$ saje.v36n1a1108

Rosenthal, R. and L. Jacobsen, 1968. Pygmalion in the Classroom: Teacher Expectation and Pupils' Intellectual Development. 1st Edn., Holt, Rinehart and Winston, New York, pp: 240.

Selvi, K., 2010. Teachers' competencies. Cultura Int. J. Philosophy Culture Axiol., 7: 167-175. DOI: $10.5840 /$ cultura20107133

Somekh, B., 2008. Factors Affecting Teachers' Pedagogical Adoption of ICT. In: International Handbook of Information Technology in Primary and Secondary Education, Voogt, J. and G. Knezek (Eds.), Springer, New York, pp: 449-460.

Stols, G., R. Ferreira, A. Pelser, W.A. Olivier and A. Wan derMerwe et al., 2015. Perceptions and needs of South African Mathematics teachers concerning their use of technology for instruction. South African J. Educ., 35: 1-13. DOI: $10.15700 /$ saje.v35n4a1209

Teimoornia, M., F. Hamidi, S.M.R.I. Jomeh and S. Foroozesh-Nia, 2011. The implementation of Information and Communication Technology (ICT) in extracurricular activities of education system in Iran. Proc. Comput. Sci., 3: 617-622. DOI: $10.1016 /$ j.procs.2010.12.103

Teo, T., 2009. Modelling technology acceptance in education: A study of pre-service teachers. Comput. Educ., 52: 302-312.

DOI: 10.1016/j.compedu.2008.08.006

Thong, J., W. Hong and K.Y. Tam, 2002. Understanding user acceptance of digital libraries: What are the roles of interface characteristics, organizational context and individual differences? Int. J. Human-Comput. Stud., 57: 215-242. DOI: $10.1016 / \mathrm{S} 1071-5819(02) 91024-4$ 
Tondeur, J., J. van Braak, G. Sang, J. Voogt and P. Fisser et al., 2012. Preparing pre-service teachers to integrate technology in education: A synthesis of qualitative evidence. Comput. Educ., 59: 134-144. DOI: 10.1016/j.compedu.2011.10.009

Woodcock, S., 2010. Diagnosing the Potential of Learning Disabilities: Understanding and Expectations of Students with Learning Disabilities. 1st Edn., Lambert Academic Publishing, Saarbrücken, Germany, ISBN-10: 3838367219, pp: 328.

Woolfolk-Hoy, A. and R. Spero, 2005. Changes in teacher efficacy during the early years of teaching: A comparison of four measures. Teach. Teacher Educ., 21: 343-356.

DOI: $10.1016 /$ j.tate.2005.01.007
Xiong, X.B. and C.P. Lim, 2015. Rethinking the impacts of teacher education program on building the ICT in education competencies of pre-service teachers: A case of teacher education in mainland China. J. Applied Res. Educ., 19: 25-35.

Zhao, Y., T. Hueyshan and P. Mishra, 2001. Technology, teaching and learning: Whose computer is it? J. Adolescent Adult Literacy, 44: 348-355. 